\title{
Modelling pure polyamide 6 hydrolysis: influence of water content in the amorphous phase
}

\author{
Deshoulles Quentin 1, 2, Le Gall Maelenn 1, Dreanno Catherine 2, Arhant Mael 1, Priour Daniel 1, \\ Le Gac Pierre Yves ${ }^{1,}{ }^{*}$
}

${ }^{1}$ Laboratoire Comportement des Structures en Mer, Ifremer, Centre de Bretagne, 29280 Plouzané,

France

${ }^{2}$ Laboratoire Détection, Capteurs et Mesures, Ifremer, Centre de Bretagne, 29280 Plouzané, France

* Corresponding author : Pierre Yves Le Gac, email address : pierre.yves.le.gac@ifremer.fr

\begin{abstract}
:
An extensive experimental study of pure hydrolysis (without oxygen) in polyamide 6 is presented in this paper. 250 micron thick film samples were immersed in pure deoxygenated water at 5 ageing temperatures for almost 2 years. Hydrolysis leads to chain scission, an increase in crystallinity and more surprisingly in a large rise in water content. A new kinetic model considering this water content increase is proposed. The modelled data are confronted with experimental values. It is mandatory to consider this increase in water content in order to be able to predict chain scission at a high level of degradation. It appears that in the absence of oxygen, hydrolysis in polyamide 6 is a slow process when the $\mathrm{pH}$ is neutral $(7 \mathrm{pH})$ and obeys an Arrhenius law with an activation energy of $106 \mathrm{~kJ} / \mathrm{mol}$. This new model can be used to predict the leaching of macromolecules from the polymer to external water that is of great interest in the framework of ocean pollution by microplastics.
\end{abstract}

\section{Highlights}

- Hydrolysis of polyamide 6 (PA6) in water without oxygen is a slow process Water content absorbed by polyamide increases significantly during hydrolysis Chain scission in polyamide 6 (PA6) due to hydrolysis process can be modelled and predicted

Keywords : Polyamide 6, Hydrolysis, Modelling, Mass Loss, Microplastic 
1) Introduction

Ocean pollution by plastics and microplastics is becoming a major environmental issue that we are now facing and will have to address in the future $[1,2]$. Microplastics are defined as small pieces of polymer, less than $5 \mathrm{~mm}$ in size [3]. In the present study, only secondary microplastics will be investigated, which, by definition, result from the degradation of a macroplastic over time $[4,5]$. In the field of polymer ageing, this subject raises new scientific questions and therefore new approaches. Usually ageing studies focus on relatively low levels of degradation that correspond to a drop in application-related properties, i.e. when the polymer can no longer be used for its application (a loss of $50 \%$ of its initial strain at break or $20-50 \%$ of its initial molecular weight $[6,7])$. The lifespan required is of the order of 20 years in the automotive industry, 30 years in the marine environment and can go up to 100 years for nuclear applications, but rarely longer. In the case of secondary microplastics, there is no service life to be attained, but rather an understanding of their degradation processes. This means that we need to be able to characterize, understand and predict the polymer's properties up to very high levels of degradation. The plastic degradation leads to the fragmentation of a macroplastic into microplastics and/or the release of macromolecules in the environment $[8,9]$. Within this scope, the present study focuses on the degradation of polyamide 6 by pure hydrolysis up to significant levels of degradation.

The hydrolysis of polyamide has been extensively studied in the literature [8,10-20]. The degradation process is described as a chemical reaction between amide and water leading to the formation of acid and amine due to a chain scission process in the polymer. When there is no oxygen, the degradation process is described as a chemical reaction between amide and water leading to the formation of acid and amine due to a chain scission process in the polymer. This chemical reaction is balanced by the polycondensation reaction. However experimental characterization of this equilibrium is often assumed and not highlighted clearly in existing studies $[12,17]$. This is a very important point when considering a very high level of degradation. From a mechanical point of view, the hydrolysis of polyamide leads to polymer embrittlement but the exact process is still unknown for the moment $[11,12,15-17,19]$. Several hypotheses have been proposed on the origin of the embrittlement during hydrolysis, such as the increase in crystallinity induced by the chemi-crystallisation process [13], the achievement of a critical molar mass in connection with tie molecules $[16,19,21]$ or a decrease in the thickness of amorphous lamellae [22]. From a long-term prediction point of view, there are several kinetic models in the literature, which will be detailed in the discussion part of this paper.

It is worth noting that the majority of kinetic studies on polyamide (PA) hydrolysis are carried out in the presence of both water and oxygen. The presence of oxygen in water plays a major role in the degradation kinetics of PA [10]. However, its contribution to chemical mechanisms remains unclear. The oxygen concentration in ocean is not constant, with very low concentration in some areas and depths [23]. At 
the same time, microplastics have been found everywhere in the oceans, from the surface water down to the seabed and even in the Arctic [24]. Therefore, to go towards a kinetic model that considers the oxygen content change in the material degradation, it is crucial to first understand the pure hydrolysis process itself. The present study, first step towards a larger investigation, is focused only on pure hydrolysis, i.e. without oxygen. The objective of this work is to propose a new kinetic model that predicts the mass loss either induced by microplastic formation or by the leaching of macromolecules due to hydrolysis.

In this work the hydrolysis of PA6 in anoxic conditions was carried out at several temperatures ranging from 80 to $140^{\circ} \mathrm{C}$. The changes in molar mass, crystallinity ratio and mass changes were recorded. The influence of the ageing temperature on the degradation process was then investigated. Finally, a section devoted to the discussion and modelling of the changes observed during ageing is proposed. 
2) Material and methods

i) Material

The polymer studied here is a polyamide 6 supplied processed by extrusion in 250 microns thick samples. Thickness has been chosen to avoid degradation profiles through the sample thickness during ageing. The main characteristics of the polymer are listed in Table 1. All samples were dried at $40^{\circ} \mathrm{C}$ under $0 \% \mathrm{RH}$ atmosphere before any test or ageing.

Table1. Measured unaged material properties

\begin{tabular}{ll}
\hline Properties & Values \\
\hline Thickness & $250 \mu \mathrm{m}$ \\
Crystallinity ratio & $19 \%$ \\
Melting point & $219^{\circ} \mathrm{C}$ \\
Glass transition (dry) & $52{ }^{\circ} \mathrm{C}$ \\
Molar mass $\left(\mathrm{M}_{\mathrm{n}}\right)$ & $52 \mathrm{~kg} / \mathrm{mol}$ \\
Strain at break (dry) & $370 \%$ \\
Stress at yield (dry) & $72 \mathrm{MPa}$
\end{tabular}

ii) Ageing Conditions

Samples were aged in deionized water within a stainless-steel pressure vessel. The water used here was purified using Millipore Elix® and was deoxygenated using a nitrogen generator (Parker Dominik Hunter G2000E) for at least 180 minutes. After complete filling of the pressure vessel with deoxygenated water, the pressure vessel was sealed and placed within an air ventilated oven (Memmert UF110). The internal hydrostatic pressure was set at 15 bars to ensure liquid water during ageing. Ageing was performed at temperatures ranging from 80 to $140^{\circ} \mathrm{C}$ for almost 2 years. More details about ageing are available in [25]. After ageing, samples were weighed and then dried in a desiccator at $40^{\circ} \mathrm{C}$ until constant mass was reached. Further characterizations were then performed.

\section{iii) Size Exclusion Chromatography (SEC)}

Molar mass was determined by SEC by the PeakExpert company according to the Laun et al. method [26]. Samples of $10 \mathrm{mg}$ were dissolved in $4 \mathrm{~mL}$ of hexafluoroisopropanol (HFiP). The dissolution was performed for $24 \mathrm{~h}$ at room temperature. The solution was then filtered using a PTFE membrane of $0.2 \mu \mathrm{m}$ thickness. The separation was performed using a pre-column and two columns packed with $7 \mu \mathrm{m}$ PFG particles, and $1000 \AA$ and $100 \AA$ pore size, the dimension of columns was $8 \mathrm{~mm}$ ID $\times 300 \mathrm{~mm}$ length. The mobile phase was a mixture of $\mathrm{HFiP}+$ $0.05 \mathrm{~mol} / \mathrm{L}$ potassium tri-fluoroacetate (KTFAc), flow rate was $1 \mathrm{~mL} / \mathrm{min}$ and injection volume was $50 \mu \mathrm{L}$. The detection was performed using a Waters 2414 differential refractive index detector and data treated with PSS WinGPC unity v7.5 SEC software. The calibration was performed using poly(methyl methacrylate) standards supplied by PSS GmbH Mainz, Germany, with molar mass ranging between 800 and 
$1.600 .000 \mathrm{~g} / \mathrm{mol}$ and the calibration curve was adjusted with a $5^{\text {th }}$ order polynomial. Calculations are conventional and average molecular weights are expressed as PMMA equivalents. Using the results from this method, it is possible to determine the chain scission in the amorphous phase of the polymer using the following equation (1) [27]:

$$
s_{\text {amorphous }}=\frac{1}{1-\chi_{c}} \times\left(\frac{1}{M_{n}}-\frac{1}{M_{n 0}}\right)(E q 1)
$$

Where $M_{n}$ is the number average molar mass, $M_{n o}$ the initial number average molar mass and $\chi_{c}$ the crystallinity ratio measured by DSC, described below. Unaged samples have been tested before each set of runs. $M_{n 0}$ value with the error is: $53.2 \pm$ $1.2 \mathrm{~kg} / \mathrm{mol}$.

iv) Differential scanning calorimetry (DSC)

Differential scanning calorimetry was used to study the modifications associated with ageing on TA instrument Q200 equipment. Polyamide 6 samples (approximatively 5 $\mathrm{mg}$ ) were heated at $10{ }^{\circ} \mathrm{C} / \mathrm{min}$ from $-40{ }^{\circ} \mathrm{C}$ to $250{ }^{\circ} \mathrm{C}$ and then cooled under a nitrogen flow of $50 \mathrm{ml} / \mathrm{min}$ according to ISO 11357-3:2018 [28]

The crystallinity ratio $\chi c$ was determined using the equation (2):

$$
\chi_{c}=\frac{\Delta H_{f}}{\Delta H_{f}^{0}} \times 100(E q .2)
$$

Where $\Delta H_{f}^{0}$ is the melting enthaipy for a $100 \%$ crystalline material (here $\Delta H_{f}^{0}=240$ $\mathrm{J} / \mathrm{g}[29,30])$ and $\Delta H_{f}$ the melting enthalpy measured here. Melting enthalpy for each sample was determined by integration of the melting peak using TA Analysis software. The melting temperature $T_{m}$ was also determined using this software. For each ageing condition, three samples were tested.

\section{v) Weight measurements}

To follow mass changes upon ageing, weight measurements are needed. For each ageing condition, the sample mass is measured at three specific times using a Sartorius LA $310 \mathrm{~S}$ balance with a resolution of $0.1 \mathrm{mg}$. First, the sample is measured before ageing in the dry state $\left(m_{0}\right)$, then directly after ageing in the wet state $\left(m_{f}\right)$ and finally after drying aged samples $\left(m_{d}\right)$. For the latter, the samples are placed in a desiccator at $0 \% \mathrm{RH}$ at $40^{\circ} \mathrm{C}$ for a minimum of 48 hours until mass reaches a plateau.

The water content is usually calculated from the initial mass and the mass at saturation, i.e. weighed when the sample is taken out of the pressure vessel. It is not the case here, as that calculation does not consider the amount of macromolecular 
chains leached from the sample. To account for this, the water content is calculated from the mass of the saturated aged sample and the mass of the same aged sample after drying. 3 samples $5 \mathrm{~cm}^{\star} 2.5 \mathrm{~cm}$ have been tested.

The water content in the polymer and the mass loss are defined according to Equations (3) and (4) respectively:

$$
\begin{aligned}
& \text { Water content }(\%)=\frac{m_{f}-m_{d}}{m_{d}} \times 100 \quad(E q .3) \\
& M a \operatorname{loss}(\%)=\frac{m_{d}-m_{0}}{m_{0}} \times 100
\end{aligned}
$$

Finally, for ease of understanding, a generic term called "mass changes", Equation (5), is used to highlight the changes in mass occurring from the initial state to the wet state. This term contains both the water content and the mass loss.

$$
\text { Mass changes }(\%)=\frac{m_{f}-m_{0}}{m_{0}} \times 100 \text { (Eq. 5) }
$$

vi) Modelling

Numerical simulation was performed using Matlab® software using the ODE45 function to solve the differential equations. 
3) Results

This section is devoted to the presentation of results obtained through characterization performed after ageing. First, test results from specimens aged at $120^{\circ} \mathrm{C}$ are presented. Then, the impact of ageing temperature is considered.

i) Molar mass changes

The PA6 ageing effect in water without oxygen at $120^{\circ} \mathrm{C}$ was investigated at the macromolecular scale using Size Exclusion Chromatography (SEC). Figure 1 shows elution curves for several ageing durations. It appears that the increase in the elution volume upon ageing is directly related to a decrease in the polymer chain length. To highlight this behaviour, the macromolecular weight $\left(\mathrm{M}_{\mathrm{n}}\right)$ is plotted as a function of ageing time in Figure 2. A large decrease from $52 \mathrm{~kg} / \mathrm{mol}$ down to $7 \mathrm{~kg} / \mathrm{mol}$ after 200 days of ageing is observed. This is associated with chain scission that is induced by the hydrolysis of the amine group in the amorphous phase $[8,14,19]$. It appears that the shape of the elution curve (Figure 1) is not greatly affected by ageing, as the polydispersity index remains constant during the entire ageing period (Figure 2). This is clear evidence of a random chain scission process.

It appears that when PA6 is immersed in water at $120^{\circ} \mathrm{C}$ a random chain scission process occurs due to hydrolysis of amide groups. This chemical degradation occurs only in this amorphous phase of the polymer; the following section will be dedicated to the characterization of the crystalline ratio during ageing.

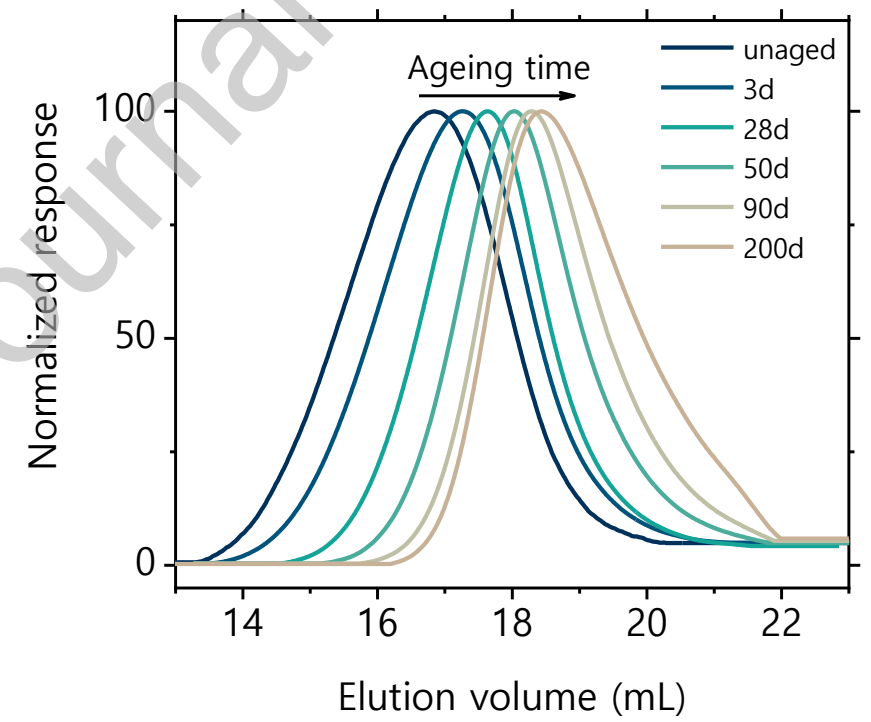

Figure 1. Changes in elution volume curves as a function of ageing. 


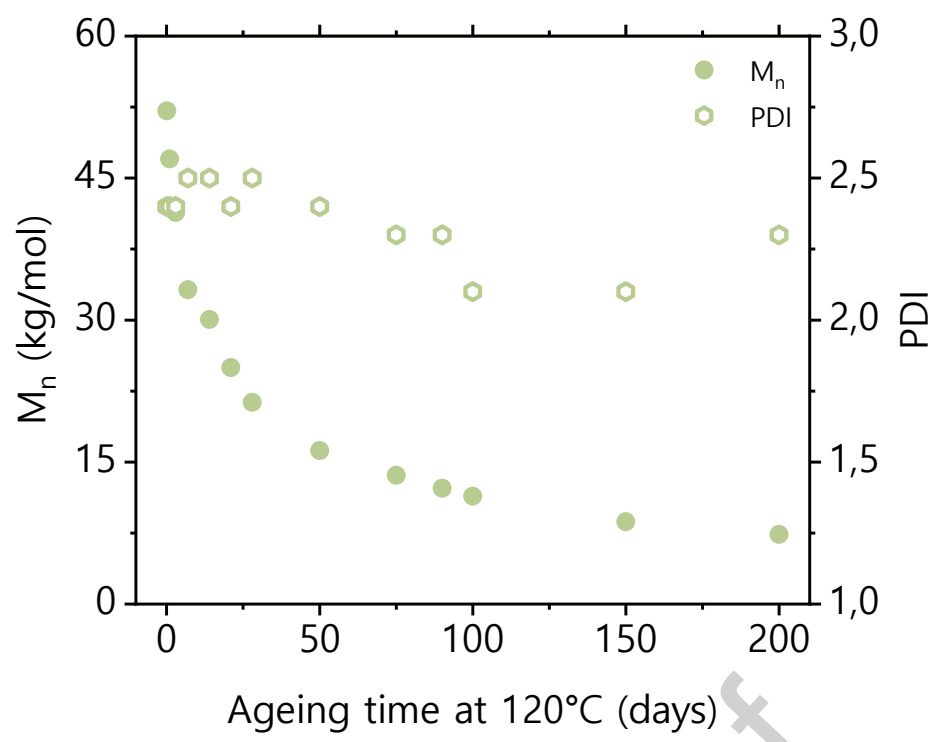

Figure 2. Molecular weight and polydispersity index as a function of ageing time at $120^{\circ} \mathrm{C}$ in water without oxygen.

\section{ii) Differential scanning calorimetry results}

In order to characterize the amount of crystalline phase found in PA6 and more especially to quantify the modifications induced during ageing, DSC was performed using exactly the same samples as those presented in section 3.1 (i.e. after ageing in water without oxygen at $120^{\circ} \mathrm{C}$ ). Thermograms for various ageing times are presented in Figure 3. Large changes are observed when samples are aged, more especially between $200^{\circ} \mathrm{C}$ and $250^{\circ} \mathrm{C}$. These are related to the melting of crystallites. In fact, an increase in the melting enthalpy can be observed due to an increase in the crystallinity as well as a modification of the melting temperature. Based on these results it is thus possible to assess the modifications in crystallinity ratio as a function of ageing duration, Figure 4. A significant increase in the crystallinity ratio is observed at the very beginning of the ageing process (from $25 \%$ up to $42 \%$ within a few minutes), which cannot be attributed to thermal crystallization, followed by a continuous increase from $42 \%$ up to $60 \%$ after 200 days. The increase in crystallinity ratio at the very early stage of ageing is attributed to a phase transformation (from beta amorphous phase to alpha crystalline phase) in the PA6 when the polymer is placed in hot water, this change does not occur in a dry environment over the same range of temperature [31,32]. The second process is induced by chain scission. During hydrolysis a decrease in chain length occurs and leads to an increase in mobility. Due to this larger mobility of macromolecules, some of them can be integrated in the crystallites. This process, named chemi-crystallisation, is much slower than the phase transformation and depends on the number of chain scission events $[7,13,25,33]$. 


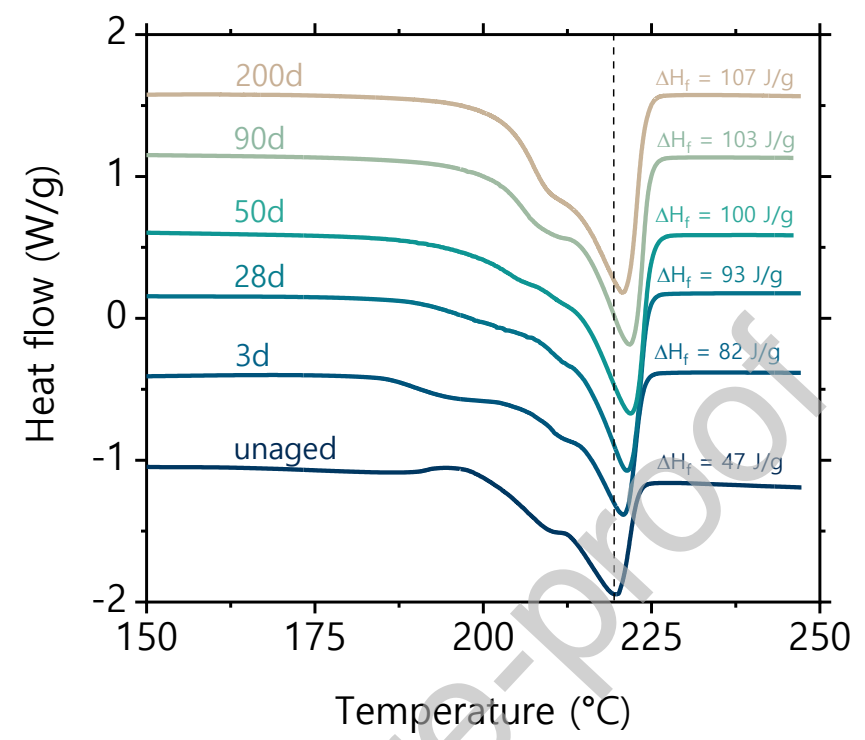

Figure 3. Thermograms as a function of ageing time at $120^{\circ} \mathrm{C}$ in water without oxygen.

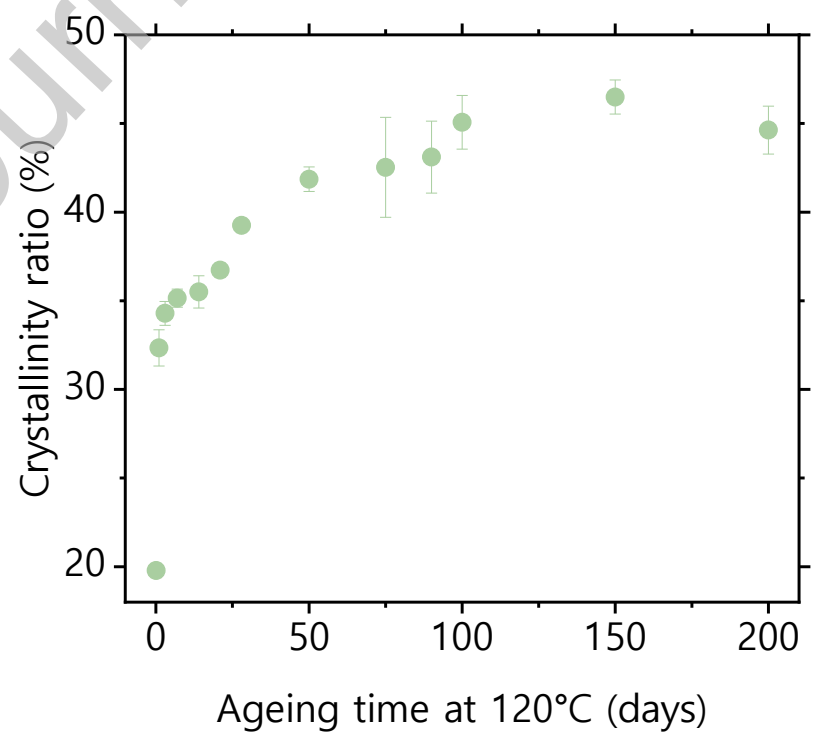

Figure 4. Crystallinity ratio as a function of ageing time at $120^{\circ} \mathrm{C}$ in water without oxygen. 
iii) Mass change

Figure 5.a reports the mass changes as a function of ageing time at $120^{\circ} \mathrm{C}$. First, a significant increase is observed up to about $10 \%$ at the very early stage (from 0 to 1 day of ageing), followed by a decrease from 10 to $8 \%$ (from 1 to 150 days of ageing).This means that two processes are involved here: first, water absorption in the PA6 and second leaching from the sample. As stated in the Method section, in order to distinguish these two competing processes, all aged samples were dried. This allowed us to assess both the water content in the polymer as well as the mass loss separately in Figure 5.b.

a) First, following the early increase in water content from 0 to $13 \%$, a second significant increase in water content up to $20 \%$ is observed as a function of ageing duration at $120^{\circ} \mathrm{C}$ (green dots in Figure 5.b). This behaviour has already been shown in the literature with PA11 [20]. In this publication, authors attributed to the incorporation of water molecules in the backbone due to the hydrolysis process. Here this increase is undoubtedly due to water absorption, because the samples were measured after drying at $40^{\circ} \mathrm{C}$ and $0 \% \mathrm{RH}$. This increase in water content can be related to the formation of polar groups induced by the hydrolysis process (amine and acid) that leads to an increase in water solubility within the polymer. This increase in water concentration will be discussed in detail later.

b) Second, a large mass loss is observed during ageing. In fact, after 150 days, more than $10 \%$ of the polymer's initial mass is lost. This mass loss probably comes from the migration of small chains from the PA6 to the water as suggested by Verdu [20]. In environmental terms, this is a major concern because macromolecular chains are released from plastic into the ocean due to polymer degradation. It is a crucial point as the impact of the presence of macromolecules on living resources remains unclear.
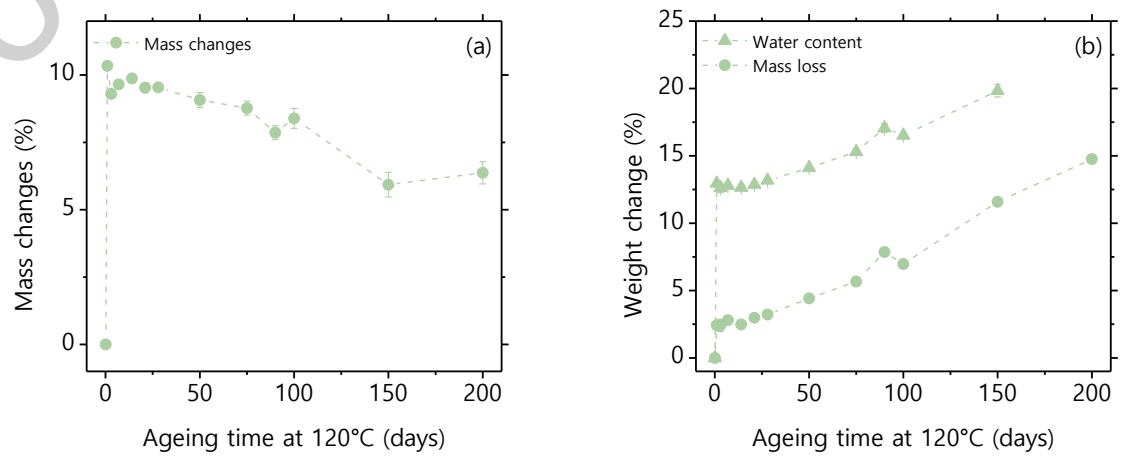

Figure 5. Mass change (a), Water Content and Mass Loss (b) as a function of ageing time at $120^{\circ} \mathrm{C}$ in water without oxygen. (error bars are covered by the symbols) 
iv) Impact of testing Temperature

All results presented in the previous sections were obtained after ageing in water at $120^{\circ} \mathrm{C}$. This section is devoted to the impact of ageing temperature on the degradation process. First, we need to verify whether or not similar trends are observed for all ageing temperatures. Second, we need to quantify the effect of temperature in order to obtain the accelerating factors. Three characteristics are followed here, chain scission in the amorphous region (Figure 6.a.), the water concentration in the amorphous region (Figure 6.b.) and the mass loss (Figure 6.c.).

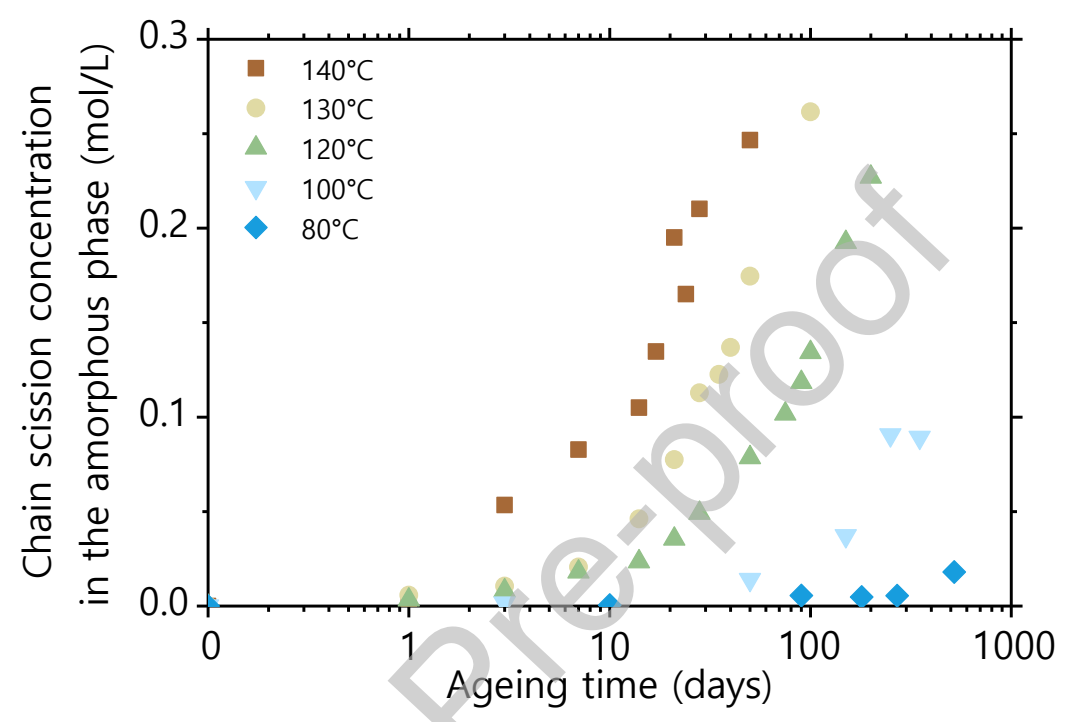

Figure 6.a. Chain scission concentration in the amorphous phase as a function of ageing time at different temperatures.

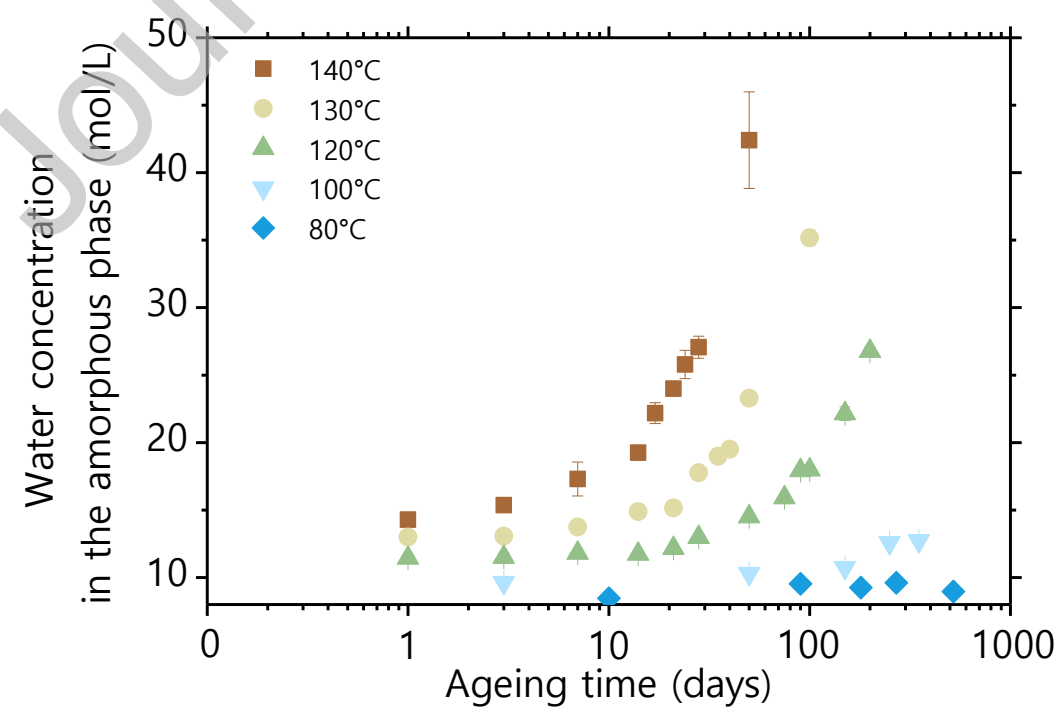

Figure 6.b. Water concentration in the amorphous phase as a function of ageing time at different temperatures. (error bars are covered by the symbols) 


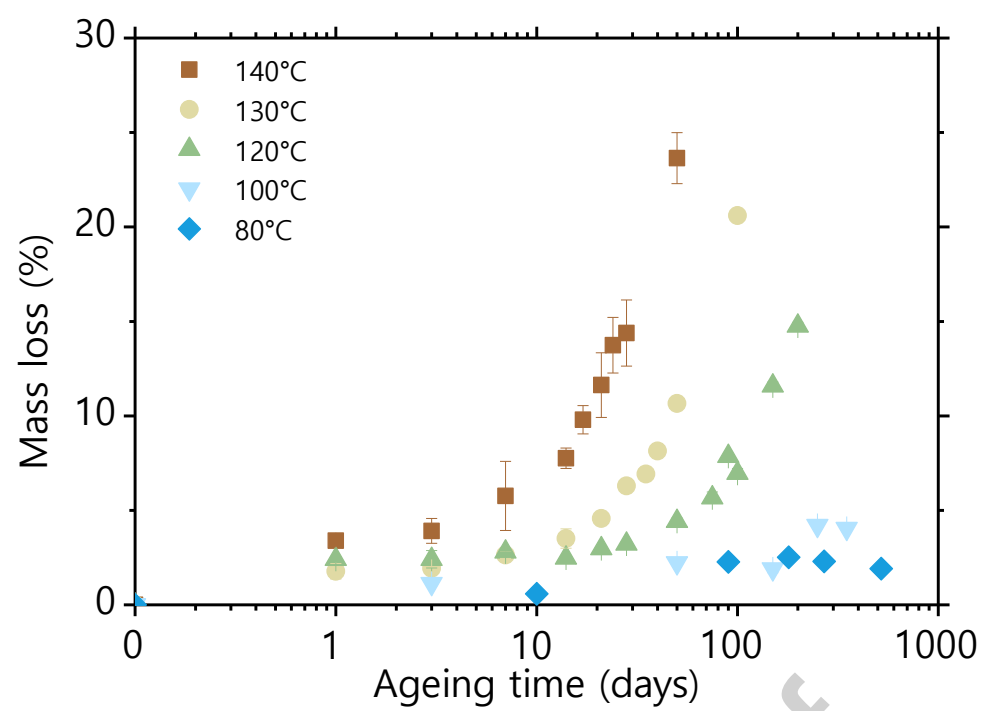

Figure 6.c. Mass loss as a function of ageing time at different temperatures. (error bars are covered by the symbols)

For all the ageing temperatures considered here, results are similar to those presented at $120^{\circ} \mathrm{C}$. Whatever the temperature, a common behaviour is identified:

An increase in chain scission concentration is observed with ageing. It is associated with the hydrolysis of the PA6 that occurs only in the amorphous region.

An increase in water concentration is observed as a function of ageing time.

- $\quad$ An increase of the mass loss is observed with ageing (for temperature down to $100^{\circ} \mathrm{C}$ ).

Moreover, as expected, an increase in ageing temperature leads to a faster degradation rate.

This raises the following question: Can we model these changes induced by ageing at different temperatures? To answer this, the next section is focused on the modelling of the results presented in Figure $6 \mathrm{a}, 6 \mathrm{~b}$ and $6 \mathrm{c}$ to try and propose a temperature dependent kinetic model for pure PA6 hydrolysis. 


\section{4) Discussion and Modelling}

The following section aims at setting up a new kinetic model that predicts chain scission in polyamide 6 when the polymer undergoes pure hydrolytic degradation. We will first focus on existing models, then the increase in water concentration with ageing will be considered in detail. Finally, particular emphasis will be placed on the mass loss during ageing as it is of major importance for the understanding of the impact of microplastics on the environment.

i) Existing models

In the literature, many kinetic models have been proposed to describe hydrolysis of polymers. Considering polyamide:

a) The hydrolysis reaction is well known and can be written as:

$$
\text { Amide }+\mathrm{H}_{2} \mathrm{O} \leftrightarrow \text { Acid }+ \text { Amine (Reaction 1) }
$$

b) Hydrolysis is not catalysed, unlike polyurethane for example [34]. This means that the chain scission rate in the amorphous region is:

$$
\frac{d s_{\text {amorphous }}}{d t}=k_{H} *[\text { Amide }] *\left[H_{2} \mathrm{O}\right]-k_{R} *[\text { Acid }] *[\text { Amine }](\text { Eq. 6) }
$$

Where $\mathrm{s}_{\text {amorphous }}$ is the chain scission concentration in the amorphous phase, $\mathrm{k}_{\mathrm{H}}$ and $\mathrm{k}_{\mathrm{R}}$ are hydrolysis and condensation rate constant, [Amide], [Acid] and [Amine] are respectively the concentrations in amide, acid and amine species and $\left[\mathrm{H}_{2} \mathrm{O}\right]$ the water concentration in the amorphous phase.

c) The reversed reaction, named polycondensation, cannot be neglected here unlike in other polymers such as PET. However it has been shown that $k_{R}$ is directly proportional to $\mathrm{K}_{\mathrm{H}}$ according to :

$$
\frac{k_{R}}{k_{H}}=e^{\frac{-(H-S T)}{R T}}(E q .7)
$$

Where $S$ is the entropy $(4 \mathrm{~J} / \mathrm{mol} / \mathrm{K})$ and $\mathrm{H}$ the enthalpy $(-24.8 \mathrm{~kJ} / \mathrm{mol})$ [35].

It worth noting that none of the models in the literature take into account the fact that water concentration in the amorphous phase increases with ageing in polyamide. This is the aim of the following section.

ii) Integration of the increase in water concentration with ageing

This section has two main objectives. The first one concerns the integration of the increase in water content during ageing within a kinetic model. The second is to 
evaluate the relevance of such a model that describes the experimental data obtained for polyamide 6 in section 3.

For all ageing conditions considered here, the water concentration in $\mathrm{mol} / \mathrm{L}$ is plotted as a function of chain scission in the amorphous phase, Figure 7. A linear relationship exists between these two parameters, whatever the ageing temperature or duration, i.e. for more than 40 different data points. This means that the water content in the amorphous phase can be described as follows:

$$
\left[\mathrm{H}_{2} \mathrm{O}\right](t)=81.8 * S_{\text {amorphous }}(t)+9.8(\text { Eq. } 8)
$$

Where $\left[\mathrm{H}_{2} \mathrm{O}\right]$ is the water concentration in the amorphous phase and $\mathrm{s}_{\text {amorphous }}$ the chain scission concentration.

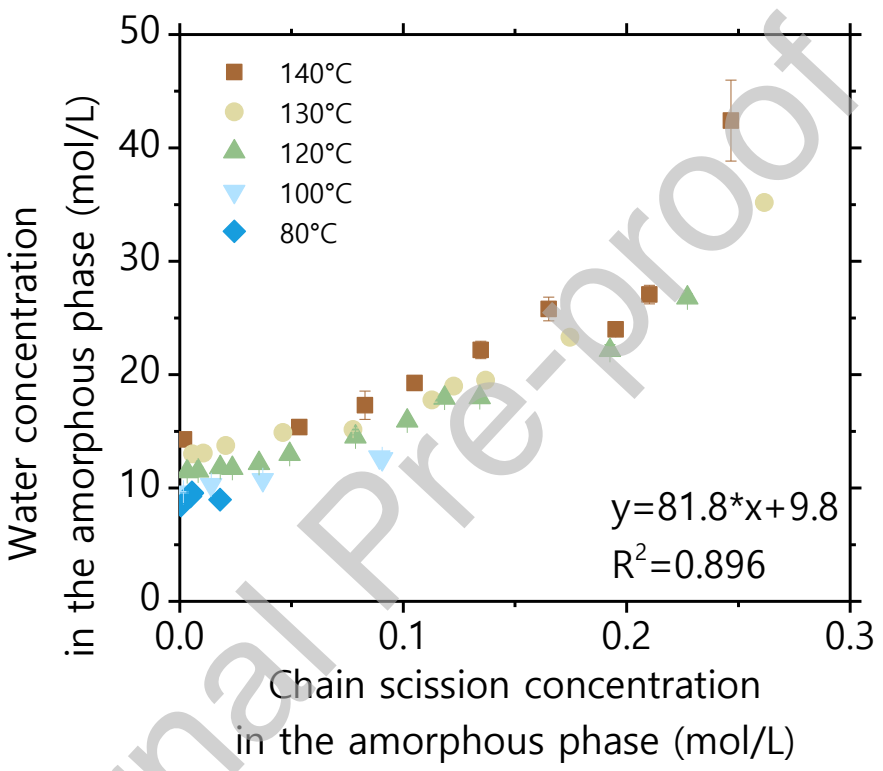

Figure 7. Relationship between water concentration in the amorphous phase and chain scission. (error bars are covered by the symbols)

Using this new relationship, it is thus possible to propose a new equation to describe chain scission during pure hydrolysis in polyamide 6 , as follows:

$$
\begin{aligned}
\frac{d s_{\text {amorphous }}}{d t}= & k_{H} *[\text { Amide }] *\left(81.8 * s_{\text {amorphous }}(t)+9.8\right)-k_{R} *[\text { Acid }] \\
& *[\text { Amine }](E q .9)
\end{aligned}
$$

Results obtained by the model at $120^{\circ} \mathrm{C}$, with and without considering the water concentration increase with ageing, are plotted in Figure 8 as well as the experimental data. It clearly appears that the increase in water content has to be included in the modelling in order to describe experimental results correctly. This is especially true for high levels of degradation. In fact, when we consider a constant water content in the polymer as is the usual assumption, the number of chain 
scissions tends towards a maximal value of about $0,15 \mathrm{~mol} / \mathrm{L}$ that is far below our experimental results $\left(0.3 \mathrm{~mol} / \mathrm{L}\right.$ at $120{ }^{\circ} \mathrm{C}$ for 200 days of ageing).

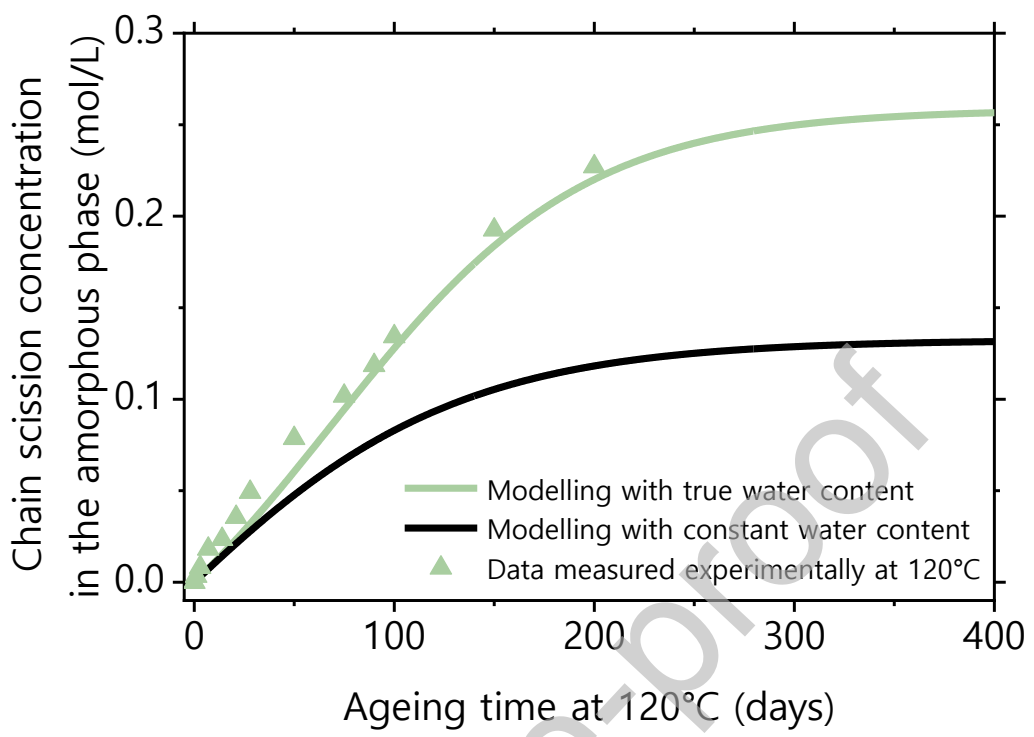

Figure 8. Comparison of chain scissions measured at $120^{\circ} \mathrm{C}$ with results of modelling with and without considering the increase in water concentration.

Results from the model are compared to those obtained from the experiments in Figure 9a. A good agreement is observed for all ageing temperatures in Figure 9a, from $80{ }^{\circ} \mathrm{C}$ to $140{ }^{\circ} \mathrm{C}$. It is thus possible to assess $\mathrm{k}_{H}$ for the 5 temperatures, these are plotted in Figure 9b. We can observe that the temperature dependence of the kinetic constant can be described using an Arrhenius behaviour with a very good correlation factor (0.99). Activation energy measured here is equal to $106 \mathrm{~kJ} / \mathrm{mol}$. It is thus possible to extrapolate the hydrolysis rate to lower ageing temperatures. To our knowledge, few published studies are available concerning pure hydrolysis of polyamide; usually the oxygen content in water is not controlled. However, based on mechanical characterization, Bernstein et al [10] have found an activation energy of $102 \mathrm{~kJ} / \mathrm{mol}$ for pure hydrolysis of polyamide 66 that is very close to the value found in our study. 

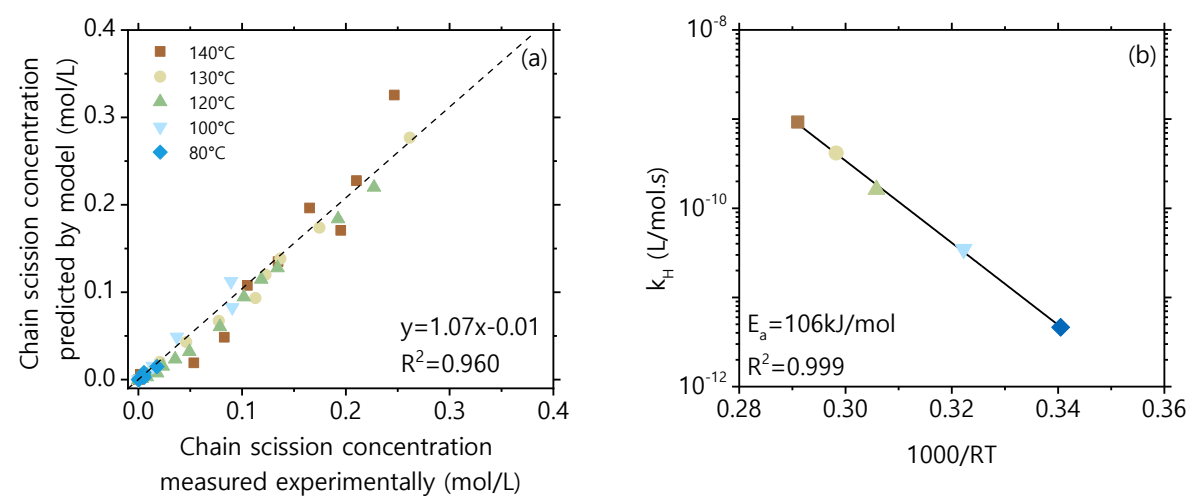

Figure 9. Results from modelling at 5 temperatures, a) comparison with experimental data, b) temperature dependence of $\mathrm{k}_{\mathrm{H}}$.

At this stage a new model that considers the increase in water content during PA6 hydrolysis has been set up. It can now be used to attempt to predict embrittlement with the same philosophy as in $[7,25,34]$ but also the mass loss during degradation. This is the aim of the following paragraph.

iii) Mass loss during hydrolysis

As observed on Figure 6c, when hydrolysis occurs, a mass loss is observed for all ageing temperatures and durations. This mass loss is attributed to the leaching of small macromolecules at the surface or close to the surface of the polymer [20]. It means that macromolecules from the polymer are leached out into the water. In order to be able to predict this leaching, we have to first propose a relationship between an output of the model, here chain scission and the mass loss. Based on results presented in Figure 10, it clearly appears that a linear relationship exists between the weight loss from the sample and the number of chain scissions, that can be written as follows:

$$
\text { Mass loss }(\%)=69.6 * s_{\text {amorphous }}
$$

Where mass loss is the weight loss during hydrolysis and $\mathrm{s}_{\text {amorphous }}$ the chain scission concentration in the amorphous phase. 


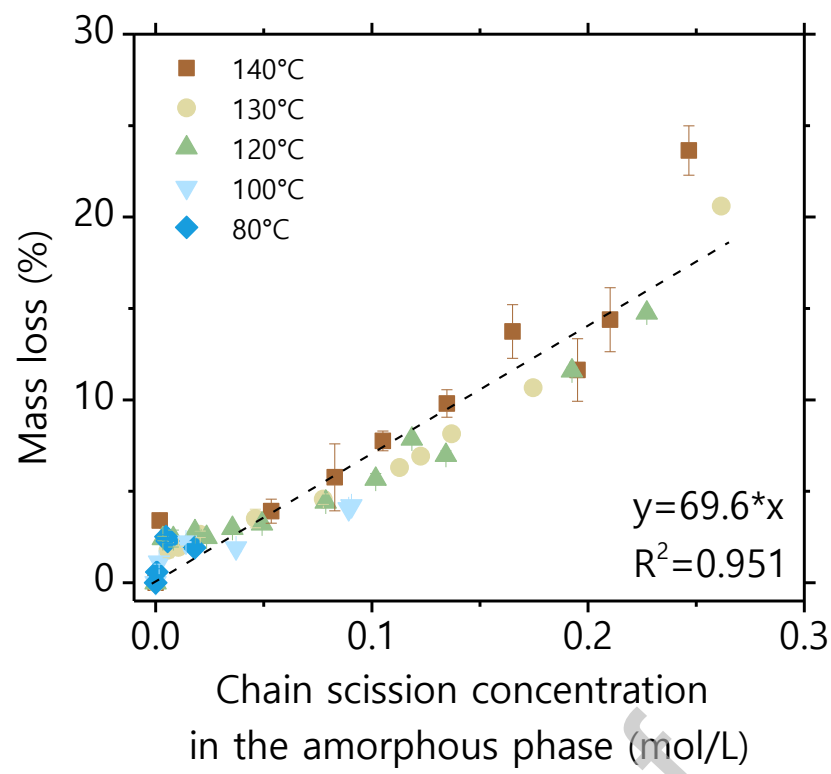

Figure 10. Mass loss as a function of chain scission for all ageing conditions considered in this study. (error bars are covered by the symbols)

Using Eq. 10 coupled with the model it is thus possible to predict the mass loss of a $250 \mu \mathrm{m}$ films that undergoes pure hydrolysis, results are plotted in Figure 11. A good agreement between predicted values and experimental data is observed.

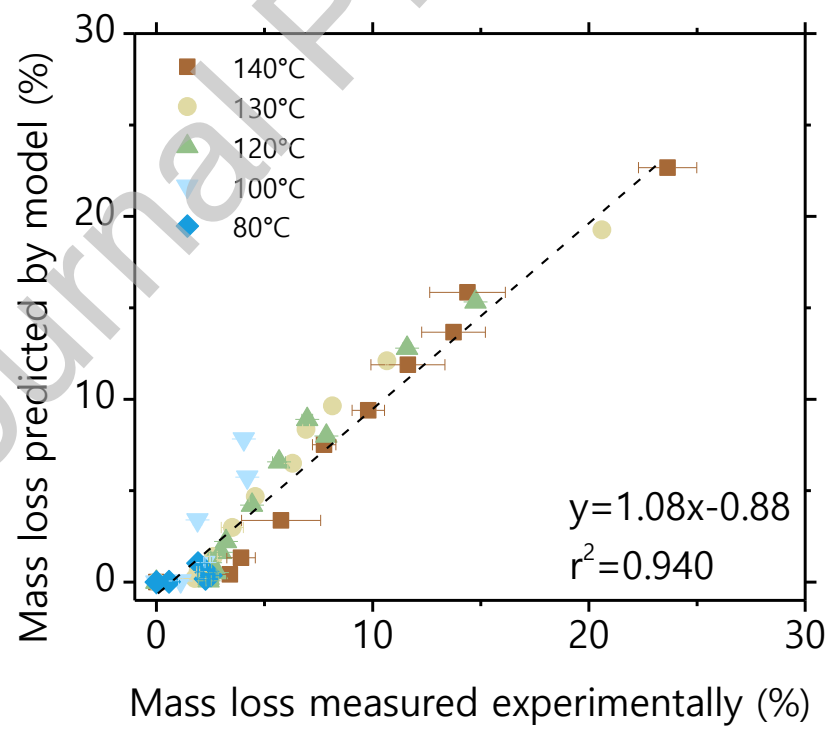

Figure 11. Mass loss in polyamide 6 during pure hydrolysis process, comparison between predicted values and experimental data. (error bars are covered by the symbols) 


\section{iv) Prediction at $25^{\circ} \mathrm{C}$}

Based on the two previous sections it appears that it is possible to predict chain scission in the amorphous phase of PA6 even at low temperature using the Arrhenius equation from Figure 9b. Moreover, a simple empirical relationship exists between mass loss due to leaching and chain scission that is independent of ageing temperature, see Figure 10. By coupling these two points it is possible to predict the mass loss from a $250 \mu \mathrm{m}$ thick film that undergoes pure hydrolysis at low temperature. As an example, at $25^{\circ} \mathrm{C}$, when only pure hydrolysis occurs, it will take more than 1000 years to leach $1 \%$ from the PA6. This predicted time is very long and suggests that pure hydrolysis is not the main origin of PA6 degradation in wet environment. The role of oxidation by thermal degradation or UV needs to be considered too.

\section{Acknowledgements}

The authors would like to thank the Microplastics project financed by IFREMER. We also thank $M$ Premel Cabick from IFREMER for his help to perform DSC measurement. 


\section{Conclusions}

Pure hydrolysis, i.e. without oxygen in water, of polyamide 6 has been experimentally studied here. Samples with a thickness of 250 microns were aged for almost two years in hot water, with temperature ranging from 140 to $80^{\circ} \mathrm{C}$. Under these conditions, a decrease in $M n$ as well as an increase in $X_{c}$ are observed due to hydrolysis of the amide bond by a random chain scission process. Moreover, a large increase in water concentration correlated with chain scission has been observed for all ageing conditions.

In order to be able to predict chain scission in polyamide 6 this increase has been integrated in a new kinetic model. This is essential in order to describe the hydrolysis process correctly. It was thus possible to determine kinetic rate values for 5 temperatures and show that the temperature dependence can be described using an Arrhenius behaviour with an activation energy of $106 \mathrm{~kJ} / \mathrm{mol}$.

Using this new model, a prediction of mass loss induced by hydrolysis can be made even at low temperature, showing that the hydrolysis process without oxygen is very slow at $25^{\circ} \mathrm{C}$. In terms of the understanding of microplastics formation or leaching of macromolecules in the environment, these results show that the pure hydrolysis of polyamide 6 will not play a major role in the very long-term behaviour of this polymer. However, existing data in the literature suggest that, in the presence of oxygen, the degradation process is much faster. This latter point will be considered in detail in another paper. 


\section{References}

[1] M. Cole, P. Lindeque, C. Halsband, T.S. Galloway, Microplastics as contaminants in the marine environment: A review, Mar. Pollut. Bull. 62 (2011) 2588-2597. https://doi.org/10.1016/j.marpolbul.2011.09.025.

[2] S.L. Wright, R.C. Thompson, T.S. Galloway, The physical impacts of microplastics on marine organisms: A review, Environ. Pollut. 178 (2013) 483492. https://doi.org/10.1016/j.envpol.2013.02.031.

[3] C. Arthur, B. Jeol E., H.A. Bamford, Proceedings of the International Research Workshop on the Occurrence, Effects, and Fate of Microplastic Marine Debris 2008, in: University of Washington Tacoma, Tacoma, WA, USA, 2009.

[4] A.L. Andrady, The plastic in microplastics: A review, Mar. Pollut. Bull. 119 (2017) 12-22. https://doi.org/10.1016/j.marpolbul.2017.01.082.

[5] A. ter Halle, L. Ladirat, X. Gendre, D. Goudouneche, C. Pusineri, C. Routaboul, C. Tenailleau, B. Duployer, E. Perez, Understanding the Fragmentation Pattern of Marine Plastic Debris, Environ. Sci. Technol. 50 (2016) 5668-5675. https://doi.org/10.1021/acs.est.6b00594.

[6] J.E. Pickett, D.J. Coyle, Hydrolysis kinetics of condensation polymers under humidity aging conditions, Polym. Degrad. Stab. 98 (2013) 1311-1320. https://doi.org/10.1016/j.polymdegradstab.2013.04.001.

[7] O. Okamba-Diogo, E. Richaud, J. Verdu, F. Fernagut, J. Guilment, B. Fayolle, Investigation of polyamide 11 embrittlement during oxidative degradation, Polymer. 82 (2016) 49-56. https://doi.org/10.1016/j.polymer.2015.11.025.

[8] N. Chaupart, G. Serpe, J. Verdu, Molecular weight distribution and mass changes during polyamide hydrolysis, Polymer. 39 (1998) 1375-1380. https://doi.org/10.1016/S0032-3861(97)00414-X.

[9] M. Deroiné, A. Le Duigou, Y.-M. Corre, P.-Y. Le Gac, P. Davies, G. César, S. Bruzaud, Seawater accelerated ageing of poly(3-hydroxybutyrate-co-3hydroxyvalerate), Polym. Degrad. Stab. 105 (2014) 237-247. https://doi.org/10.1016/j.polymdegradstab.2014.04.026.

[10] R. Bernstein, D.K. Derzon, K.T. Gillen, Nylon 6.6 accelerated aging studies: thermal-oxidative degradation and its interaction with hydrolysis, Polym. Degrad. Stab. 88 (2005) 480-488. https://doi.org/10.1016/j.polymdegradstab.2004.11.020.

[11] C. El-Mazry, O. Correc, X. Colin, A new kinetic model for predicting polyamide 66 hydrolysis and its mechanical embrittlement, Polym. Degrad. Stab. 97 (2012) 1049-1059. https://doi.org/10.1016/j.polymdegradstab.2012.03.003.

[12] S. Hocker, A.K. Rhudy, G. Ginsburg, D.E. Kranbuehl, Polyamide hydrolysis accelerated by small weak organic acids, Polymer. 55 (2014) 5057-5064. https://doi.org/10.1016/j.polymer.2014.08.010.

[13] S.J.A. Hocker, W.T. Kim, H.C. Schniepp, D.E. Kranbuehl, Polymer crystallinity and the ductile to brittle transition, Polymer. 158 (2018) 72-76. https://doi.org/10.1016/j.polymer.2018.10.031.

[14] B. Jacques, M. Werth, I. Merdas, F. Thominette, J. Verdu, Hydrolytic ageing of polyamide 11. 1. Hydrolysis kinetics in water, Polymer. 43 (2002) 6439-6447. https://doi.org/10.1016/S0032-3861(02)00583-9.

[15] P.-Y. Le Gac, B. Fayolle, Impact of fillers (short glass fibers and rubber) on the hydrolysis-induced embrittlement of polyamide 6.6, Compos. Part B Eng. 153 (2018) 256-263. https://doi.org/10.1016/j.compositesb.2018.07.028. 
[16] S. Maïza, X. Lefebvre, N. Brusselle-Dupend, M.-H. Klopffer, L. Cangémi, S. Castagnet, J.-C. Grandidier, Physicochemical and mechanical degradation of polyamide 11 induced by hydrolysis and thermal aging, J. Appl. Polym. Sci. 136 (2019) 47628. https://doi.org/10.1002/app.47628.

[17] T. Mazan, R. Berggren, J.K. Jørgensen, A. Echtermeyer, Aging of polyamide 11. Part 1: Evaluating degradation by thermal, mechanical, and viscometric analysis, J. Appl. Polym. Sci. 132 (2015). https://doi.org/10.1002/app.41971.

[18] I. Merdas, F. Thominette, J. Verdu, Hydrolytic ageing of polyamide 11-effect of carbon dioxide on polyamide 11 hydrolysis, Polym. Degrad. Stab. 79 (2003) 419-425. https://doi.org/10.1016/S0141-3910(02)00358-0.

[19] A. Meyer, N. Jones, Y. Lin, D. Kranbuehl, Characterizing and Modeling the Hydrolysis of Polyamide-11 in a pH 7 Water Environment, Macromolecules. 35 (2002) 2784-2798. https://doi.org/10.1021/ma0105410.

[20] G. Serpe, N. Chaupart, J. Verdu, Ageing of polyamide 11 in acid solutions, Polymer. 38 (1997) 1911-1917. https://doi.org/10.1016/S0032-3861(96)007057.

[21] C. El-Mazry, M. Ben Hassine, O. Correc, X. Colin, Thermal oxidation kinetics of additive free polyamide 6-6, Polym. Degrad. Stab. 98 (2013) 22-36. https://doi.org/10.1016/j.polymdegradstab.2012.11.002.

[22] M.A. Kennedy, A.J. Peacock, L. Mandelkern, Tensile Properties of Crystalline Polymers: Linear Polyethylene, Macromolecules. 27 (1994) 5297-5310. https://doi.org/10.1021/ma00097a009.

[23] K. Wyrtki, The oxygen minima in relation to ocean circulation, Deep Sea Res. Oceanogr. Abstr. 9 (1962) 11-23. https://doi.org/10.1016/0011-7471(62)902437.

[24] S. Morgana, L. Ghigliotti, N. Estévez-Calvar, R. Stifanese, A. Wieckzorek, T. Doyle, J.S. Christiansen, M. Faimali, F. Garaventa, Microplastics in the Arctic: A case study with sub-surface water and fish samples off Northeast Greenland, Environ. Pollut. 242 (2018) 1078-1086. https://doi.org/10.1016/j.envpol.2018.08.001.

[25] M. Arhant, M. Le Gall, P.-Y. Le Gac, P. Davies, Impact of hydrolytic degradation on mechanical properties of PET - Towards an understanding of microplastics formation, Polym. Degrad. Stab. 161 (2019) 175-182. https://doi.org/10,1016/j.polymdegradstab.2019.01.021.

[26] S. Laun, H. Pasch, N. Longiéras, C. Degoulet, Molar mass analysis of polyamides-11 and -12 by size exclusion chromatography in HFiP, Polymer. 49 (2008) 4502-4509. https://doi.org/10.1016/j.polymer.2008.08.017.

[27] O. Saito, 11 - Statistical Theories of Cross-Linking, in: M. Dole (Ed.), Radiat. Chem. Macromol., Academic Press, 1972: pp. 223-261. https://doi.org/10.1016/B978-0-12-219801-4.50017-3.

[28] 14:00-17:00, ISO 11357-3:2018, ISO. (n.d.). https://www.iso.org/cms/render/live/fr/sites/isoorg/contents/data/standard/07/24/ 72460.html (accessed April 20, 2020).

[29] K.-H. Illers, Polymorphie, kristallinität und schmelzwärme von poly( $\varepsilon$ caprolactam), 2. Kalorimetrische untersuchungen, Makromol. Chem. 179 (1978) 497-507. https://doi.org/10.1002/macp.1978.021790224.

[30] C. Millot, L.-A. Fillot, O. Lame, P. Sotta, R. Seguela, Assessment of polyamide-6 crystallinity by DSC, J. Therm. Anal. Calorim. 122 (2015) 307-314. https://doi.org/10.1007/s10973-015-4670-5. 
[31] J. Gianchandani, J.E. Spruiell, E.S. Clark, Polymorphism and orientation development in melt spinning, drawing, and annealing of nylon-6 filaments, J. Appl. Polym. Sci. 27 (1982) 3527-3551. https://doi.org/10.1002/app.1982.070270928.

[32] G. Gurato, A. Fichera, F.Z. Grandi, R. Zannetti, P. Canal, Crystallinity and polymorphism of 6-polyamide, Makromol. Chem. 175 (1974) 953-975. https://doi.org/10.1002/macp.1974.021750322.

[33] A. Ballara, J. Verdu, Physical aspects of the hydrolysis of polyethylene terephthalate, Polym. Degrad. Stab. 26 (1989) 361-374. https://doi.org/10.1016/0141-3910(89)90114-6.

[34] A. Bardin, P.-Y. Le Gac, S. Cérantola, G. Simon, H. Bindi, B. Fayolle, Hydrolytic kinetic model predicting embrittlement in thermoplastic elastomers, Polym. Degrad. Stab. 171 (2020) 109002. https://doi.org/10.1016/j.polymdegradstab.2019.109002.

[35] K. Tai, T. Tagawa, Simulation of hydrolytic polymerization of .epsilon.caprolactam in various reactors. A review on recent advances in reaction engineering of polymerization, Ind. Eng. Chem. Prod. Res. Dev. 22 (1983) 192206. https://doi.org/10.1021/i300010a007.

\section{Declaration of interests}

$\bigotimes$ The authors declare that they have no known competing financial interests or personal relationships that could have appeared to influence the work reported in this paper.
Q. Deshoulles - Investigation
M. Le Gall - Investigation
C. Dreanno - Investigation
M. Arhant - Investigation
D. Priour - Investigation
P-Y. Le Gac- Investigation 